Portland State University

PDXScholar

1979

\title{
A study of psoriasis : a methodological critique
}

\author{
Prudence Craig Ford \\ Portland State University \\ Roberta Jeanne Ford \\ Portland State University \\ Susan Swanson \\ Portland State University
}

Follow this and additional works at: https://pdxscholar.library.pdx.edu/open_access_etds

Part of the Community-Based Research Commons, and the Medicine and Health Commons Let us know how access to this document benefits you.

\section{Recommended Citation}

Ford, Prudence Craig; Ford, Roberta Jeanne; and Swanson, Susan, "A study of psoriasis : a methodological critique" (1979). Dissertations and Theses. Paper 2688.

https://doi.org/10.15760/etd.2684

This Thesis is brought to you for free and open access. It has been accepted for inclusion in Dissertations and Theses by an authorized administrator of PDXScholar. Please contact us if we can make this document more accessible: pdxscholar@pdx.edu. 


\title{
A STUDY OF PSORIASIS: A METHODOLOGICAL CRITIQUE
}

\author{
by
}

PRUDENCE CRAIG FORD

ROBERTA JEANNE $\mathrm{KOCH}$

SUSAN SWANSON

A practicum submitted in partial fulfillment of the requirements for the degree of

MASTER OF SOCIAL WORK

Portland State University 
TABLE OF CONTENTS

PAGE

CHAPTER

I INTRODUCTION . . . . . . . . . . . . . . . 1

Background Information: Psoriasis . . 1

Background Information: Original

Study . . . . . . . . . . . 3

Review of the Literature . . . . . . 5

Original Study . . . . . . . . . . . . 11

II METHODOLOGY . . . . . . . . . . . . . . 16

Original Study . . . . . . . . . . . . 16

The Instrument

The Pre-test

Selection and Characteristics of the Subjects

Procedure for Data Collection

Data Analysis

The Critique . . . . . . . . . . . . . 21

Format (Instrument)

Review of the Literature

Review of Project Records and Notes

III THE CRITIQUE . . . . . . . . . . . . 23

The Research Group . . . . . . . . 23

Composition and Orientation

Problems in Carrying Out the Study 
Problem Formulation . . . . . . . . .

Purpose

Auspices

Orientation of Researchers and

Use of the Literature

Research Questions

Hypotheses and Variables

Research Design and Data Collection . .

Design

Survey Population

Sampling Methods

Interview Schedule

Reliability and Validity of

Criterion Measures

Pre-test

Data Collection

Data Analysis . . . . . . . . . . .

Pre-coding

Statistics

Summary . . . . . . . . . . . . . 35

IV SUMMARY AND CONCLUSIONS . . . . . . . . . 36

Summary of Findings . . . . . . . . . 36

Implications of the Study . . . . . . 38

Implications for the Education of Social Work Students

Implications for the Field of Social Work

Implications for Further Research on Psoriasis

Conclusion

REFERENCES CITED . . . . . . . . . . . . . . . . . . 40 APPENDIX . . . . . . . . . . . . . . . . . . . 43 


\section{CHAPTER I}

\section{INTRODUCTION}

The purpose of this report is to assess the research design and methodology of a 1978 survey of psoriatic members of the National Psoriasis Foundation, located in Portland, Oregon. The study was suspended for reasons beyond the control of the student researchers involved.

\section{BACKGROUND INFORMATION: PSORIASIS}

According to the National Psoriasis Foundation (1976), psoriasis is a little known and poorly understood skin disease afflicting an estimated eight million victims in the United States. About fifteen thousand new cases of psoriasis are diagnosed each year. It affects men and women in equal numbers at any age, most often between the ages of fifteen and thirty-five.

Although the disease has been known to mankind since Biblical times, there is no cure. Even the cause is not understood. Anyone may develop psoriasis, at any time of life. The disease is known to have hereditary factors, but the inheritance pattern is not clearly established.

Psoriasis is a skin disease known by its wildly accelerated cell growth process. Normal cell growth maturity is 
in twenty-eight to thirty days. In skin affected by psoriasis, cells form in six to eight days and never fully mature. The dead skin cell layers form unsightly silver patches called plaques. The plaques slough off in conspicuous silvery flakes. Beneath the plaque, the skin is red and blotchy.

The disease can be found on any part of the body. It commonly affects the knees, elbows, and scalp. No skin surface is immune. It can be mild, severe, or in some rare cases, fatal. It can disappear suddenly, reappear without warning, and not reappear in the same place. Approximately 10 percent of psoriatics suffer from psoriatic arthritis. The arthritis is attributed to massive internal tissue growth related to psoriasis.

Many treatments in common use today have a long history. Tar-based ointments, used alone or in combination with natural sunlight or ultraviolet lamps, have been prescribed by generations of physicians. Cortisone ointments are sometimes prescribed, often in conjunction with air-tight plastic wrappings to help the medication penetrate the skin. Drugs which inhibit cell growth have been used in severe cases. Researchers across the country are now testing an experimental treatment called photochemotherapy. The ingestion of special drugs makes the skin highly sensitive to ultraviolet light. After the drug is taken, the psoriatic 
spends a short time under a mass of specially manufactured longwave ultraviolet lights.

In the treatment of the disease there are many problems. Prescription and skin ointments are costly, especially when they must be repeatedly applied to large skin areas. Repeated office visits are both necessary and expensive. Hospital treatments are costly. Some cities have developed day care centers, where the psoriatic may receive treatment during the day, and return home at night. This is less costly than round-the-clock hospital care.

Home treatments or day care provisions can still be so time consuming as to interfere with employment and normal family and social life. The exact figures are not known, but it is estimated that fifty-six million man hours of work are lost each year by people who suffer from psoriasis. Another $\$ 1$ billion is spent on treatment. Some psoriatics become treatment "dropouts" and seclude themselves at home. These near-recluses are a tragic loss to society.

\section{BACKGROUND INFORMATION: ORIGINAL STUDY}

The National Psoriasis Foundation has been concerned since its inception in 1966 about the many problems that confront the psoriatic members of the population. Because the Foundation is relatively young and without many resources, its data base is somewhat sparse; no extensive survey had been conducted at the state or national level with 
a special emphasis on the needs, problems, and selfperceptions of the psoriatic person. If the Foundation is to be responsive to the needs of its members, engage in comprehensive planning, and provide information to the public, it must have a repository of accurate data. Such data must reflect the concerns, needs, and perceptions of psoriatics themselves.

With a $\$ 4$ thousand grant received from the Texas Pharmaceutical Company, The Psoriasis Foundation approached the School of Social Work, Portland State University, in the spring of 1978, requesting help in conducting a survey of al1 the members of the Oregon, Washington, Montana, and Idaho chapters of the National Psoriasis Foundation for the purpose of (1) establishing a data base from which the Foundation could determine the informational and service needs of its members, (2) determining whether a day treatment center would be supported and utilized by its members, and (3) establishing a data base for future study.

The author of the grant was a board member of the Foundation who was also a faculty member at the School of Social Work. This individual became the primary investigator for the project. He organized a study team consisting of himself, three social work students, and a paid research assistant whose function was to help in the collection, categorization, and analysis of data. 
The students' particular interest in participating in this study was to learn how the disease affected its victims in ways other than "a person with a diseased skin." Since no extensive survey had been conducted in this area before, we felt this information had important implications for medical social workers in developing an understanding of the problems confronting a psoriatic patient. The psycho-social factors and coping processes of a patient are necessary elements to consider in the process of treatment, if professional care-givers wish to assist in the psychological as well as the physiological healing process (Moss 1977). To begin this study, we realized that we needed to develop an understanding of the disease itself.

The extent of the students' knowledge of the disease went no further than hearing crass and thoughtless jokes, and commercial presented on television about the "Heartbreak of Psoriasis." To develop a better understanding, staff members of the Foundation were interviewed, descriptive examples of diseased individuals were viewed on film, and hospitalized patients were visited. Literature on this topic added additional insight into this area.

\section{REVIEW OF THE LITERATURE}

An extensive literature search was made to familiarize ourselves with the disease. We were interested in reviewing all available research on this little-known disease in an 
attempt to define particular problem areas that could lead to further investigation. In so doing, a search was made through medical journals, social work journals, sociology and psychology journals, and the files at the Foundation.

The medical social worker is known to contribute importantly towards the understanding and treatment of various debilitating diseases, but we found no mention in the social work journals of the use of casework methods in the treatment of dermatological problems, let alone psoriasis. Only scant references were made in any of the other journals on the personal and social impact of the disease, and the problems the individual might encounter as a direct result of being a victim of the disease.

In the medical literature there was a copious supply of information concerning the medical management and etiology of the disease, as well as the demographic variations found throughout the world.

In the emotional area, some investigators, in the process of investigating causal factors of the disease, studied the relationship between psoriasis and emotional disturbances. Others related the disease to degrees of stress and worry.

Graham (1954) reported that a relationship between emotional disturbance and this disease had been mentioned from time to time for many years. Mackenna (1944) considered that chronic psoriasis is often linked with deeply 
repressed emotional conflicts, and that the presence of itching generally indicates that emotional factors may be responsible for the persistence of the eruptions. Wittkower (1946), Obermeyer (1958), Susskind and McGuire (1959), and more recently Baughman and Sobel (1971), found no specific personality profile for psoriatic patients. Goldsmith, Fisher, and Wacks (1969) also failed to find any significant differences between the psoriatic and control groups with reference to its two parameters of neuroticism and extraversion.

Although investigators evaluated the role of emotional factors in their psoriatic patients and attempted to define the degree of "neuroticism" in the patients, they concluded that psoriatic patients cannot be considered significantly more neurotic than the general population. This does not eliminate the relationship between life stresses and the disease (Wittkower 1946, and Obermeyer 1958).

Graham (1954) further studied the association of life stresses and cutaneous vascular reactions in psoriasis. A1though his sample consisted of only ten patients, he concluded there was a clear-cut temporal correlation between the presence of disturbing life situations and onset or flare-ups of psoriasis. Susskind and McGuire's 1959 study of twenty patients found that life situations involving the mobilization of severe anxiety and unexpressed resentment 
occurred in relation to the disease in eight cases, and with exacerbations in fourteen cases.

The role of worry and its relationship to psoriasis was presented by Farber and Bright (1968). In a more recent study by Farber and Nall (1974), to the query presented to fifty-six hundred patients, "At times of worry, do new patches of psoriasis appear?" one-third responded affirmatively, one-third said there was no effect, and one-third were uncertain. In the series of Braun-Falco et al. (1972) of 536 psoriasis patients, 42 percent reported that worry produced an exacerbation. Baughman and Sobe1 (1971) applied a mechanical stress-strain model in approaching the possible relationship of psychological factors to psoriasis by a questionnaire technique in over two hundred previously hospitalized psoriasis patients. They concluded that stress and personality play less important roles than many have assumed. Sabin (1970), however, reported that 50 percent of a series related psoriasis to worry. A survey of 245 children with psoriasis in Denmark revealed that 90 percent worsened following stress (Nyfors and Lemholt 1975).

These studies indicate that subjective factors do not always correlate with biological phenomena, although there is enough evidence to say there is an association between stress and the acceleration of the disease (Farber and Nall 1974). 
Susskind and McGuire (1959) were among the few investigators who looked at the stress/disease phenomena conversely. In other words, the impact of living with the disease is stress producing. They state:

The effect of the disease on the patient may be an important feature. The patient at home and at work may be exposed to a social environment of curiosity, hostility, and disgust because his skin is "unclean." His family and workmates may wonder, 'will it spread to me?' and the possibility of a connection with venereal disease may not be far from their minds. These factors may lead to much embarrassment and may limit or affect the patient's sexual and social relationships. This situation is referred to by MacKenna (1944) as the leper complex.

As Thompkins reiterated in a latter statement:

". . being unsightly and disfiguring, the lesions may cause irreversible emotional stigma in those with extensive psoriasis" (1973). "For children as well as adults skin disease is repugnant," say Farber and Carlsen (1966) in their study of 268 cases of childhood psoriasis cared for at the Stanford-Palo Alto Hospital Outpatient Clinics.

In a survey of fifty-eight psoriatic patients, Savin (1970) found 36 percent reported self-consciousness because of the disease, 25 percent depression. Fifty percent associated worry with the disease, and many noted this worsened the psoriasis, thus generating a vicious cycle. Twentyfour percent of those surveyed had given up swimming because of visible lesions.

Jobling (1976) in a study of 186 psoriatics found 84 percent of them reporting difficulties in establishing 
social contacts and relationships. Though only a small percentage of them had actually experienced social avoidance or exclusion, anticipation of it was ever present. Other difficulties mentioned by the subjects included the need to wear clothing to conceal the psoriasis, and being stared at and questioned about the psoriasis.

Coles and Ryan (1975) suggest that attention to the psychological aspects might possibly reduce more rashes than ointments do.

As Beverly W. Foster, founder and director of the $\mathrm{Na}-$ tional Psoriasis Foundation, stated to a congressional appropriations committee after examining hundreds of letters received by the Foundation:

Psoriasis rarely kills, but it destroys the lives of millions of people. While most cases are mild and can be fairly well controlled, even these may flare up and worsen at any time. In its more severe forms, psoriasis is a disabling, disfiguring scourge that mutilates people physically, psychologically, and socially (Cole 1974).

In conclusion, our research of the literature indicated a large accumulation of research on the medical components of the disease. In other words, methods of medical treatment, the development of a medical profile of the patient, and a search for the etiology of this "disease" of the skin had been the foci.

A number of studies over a span of twenty years were made to determine a relationship between the disease and a possible neurotic personality in attempts to find causal 
factors to the disease. Although these studies revealed no specific personality profile, there was evidence of an association between stress and the acceleration of the disease. A few investigators took this phenomenon a step further and studied the effects of living with the disease, and found supporting evidence that the disease was disfiguring physically, psychologically, and socially.

We saw this latter area as neglected in the literature. Understanding the psoriatics' perceptions of the problems of having the disease is necessary if professionals wish to help in the psychological healing process.

\section{ORIGINAL STUDY}

With this background in mind, an exploratory study was conducted to survey the numbers, needs, and perceived problems of the chapter members of the National Psoriasis Foundation residing in the four regional northwest states.

Numbers referred to how many chapter members were or had been afflicted with the disease.

Needs referred to material necessities such as financial, employment, medical treatment, and/or treatment facilities.

Perceived problems reflected the sufferer's experience of the disease, and the concommitant personal and social problems with which he had to cope. 
The assumption that individuals suffering from psoriasis were afflicted in some degree in the six areas listed below led to the following questions:

1. Personal. What is the reaction of the psoriatic to his disease? Has it changed his perception of self? Does he have a sense of being different from other people because he has psoriasis? Does he feel anxious, guilty, irritable, depressed as a result of having psoriasis?

2. Family. How has having psoriasis affected his relationship with his family? Does having psoriasis mean spending less time with his family because of time in the hospital, professional treatment, or self-care? Are family members knowledgeable about psoriasis, and are they understanding and supportive?

3. Social. What effect has psoriasis had on relationships outside the family? Have former friendships been maintained? Does he engage in cultivating new friendships? Does he isolate himself from other people because he has psoriasis?

4. Community. Has the psoriatic's acceptance and participation in the community been limited by his disease? Has it ever interfered with going to the barber shop or beauty salon, public swimming pools or beaches, etc.? 
5. Economic. What is the cost of the disease in terms of cost of treatment, hospitalization, and work lost?

6. Employment. Has the psoriatic ever been refused a job because of his skin disease? Has psoriasis affected his choice of occupation?

In addition to fulfilling goals designed by the Foundation, a special emphasis was also placed on collecting information that would be useful for the enhancement of medical social work practice. Hopefully, the project would help social workers in a medical setting better understand the special problems confronting the psoriatic patient.

An interview schedule was designed to collect data from a selected sample of members residing in Portland, Eugene, and Roseburg, Oregon. A mail questionnaire was designed to reach the remaining membership population.

After the design of the instruments, the study became fraught with difficulties which ultimately resulted in its being halted. The total study remains incomplete at the time of this report due to the circumstances which follow. Before the end of the spring school term, the principal investigator terminated his faculty position at the school of Social Work, and at the same time relinquished his leadership position in the research study. The students were advised to continue participation in the study through the summer months, and establish new faculty advisorship in 
the fall. The Foundation appointed the research assistant as project leader.

At this time, the team was increased by two members. A medical student was brought in by a member of the advisory board to assist in the personal interviews and the tabulation of data. Douglas County Public Hea1th Department joined the project and provided an interviewer to cover the Roseburg area. Foundation administrative personnel became more actively involved in keeping track of the progress of the study.

Team members' responsibilities then became divided. The administering of the interview schedules became the responsibility of the social work students and the two new team nembers. The Foundation and the project leader took responsibility for the distribution of the mail questionnaire. Eighty percent of the scheduled interviews were successfully completed. The response to the mail questionnaire, however, was 12 percent. The low rate of return resulted in several members of the Foundation's advisory board becoming actively involved in an evaluation to determine the causal factors for the low response. In the process of the investigation, it was determined that there were methodological deficiencies in the distribution process of the mail questionnaire. The deficiencies were such that any analysis of data would be of questionable significance. 
The project leader was relieved of his position, and the project suspended until a later comprehensive follow-up study could be resumed.

The following fall (1978), the students acquired a new faculty advisor. The decision was made that because of the poor sampling method, the tabulation and analyzing of the data from the interviews would be of questionable significance.

Instead, the authors will critically evaluate the methodology of the original study, omitting in this critique the mail questionnaire, since the students were not directly involved in its distribution.

We hope to produce a critique useful not only in forthcoming studies of the National Psoriasis Foundation, but also to other students in similar circumstances. We see the product as a modest contribution to the methodology 1iterature. 
CHAPTER II

\section{METHODOLOGY}

The methodology chapter will be divided into two sections. The first section will describe the methodology for the original study. The second part will show the methodology for the critique of the original study.

\section{ORIGINAL STUDY}

Due to the paucity of research on the sociological and psychological implications of psoriasis, an exploratory design was used for the study. Data were collected by interviewing persons with psoriasis.

\section{The Instrument}

The instrument used for data collection took the form of an interview schedule, devised by the research group specifically for the study.

The interview schedule was devised for administration to individuals who were victims of psoriasis. The questions presented in the questionnaire were a combination of closed and open-ended type. It was the opinion of the researchers that the open-ended questions would allow for more in-depth subjective answers from respondents. 
The interview schedule contained forty items, and is presented in the Appendix. The schedule items were grouped into five areas of concern.

The first section elicited demographic information such as age, sex, marital status, occupation, and income.

The second section elicited responses regarding the subject's view of the characteristics and severity of his psoriasis.

The third section elicited information regarding perceived problems of the psoriatic in the areas of his life affected by psoriasis: personal, family, social, community, economic, and work.

The fourth section elicited information regarding treatment of psoriasis, including availability, accessibility, and cost.

The fifth section of the questionnaire asked what information the respondent had regarding day treatment centers for psoriatics, and if such a center were available, whether they would use it.

The instrument was reviewed by staff and volunteer workers of the Foundation, and by members of the advisory board, to insure that the technical information was correct and up-to-date, and that the questions were appropriate and answerable. 
The Pre-test

The instrument was pre-tested by interviewing members of the National Psoriasis Foundation selected from the mailing 1ist. The purpose of the pre-test was to determine whether the questions were understandable by the respondents. The instrument was refined by re-wording some questions.

Selection and Characteristics of the Subjects

Subjects for the personal interviews were selected from the mailing list of the membership of the National Psoriasis Foundation, the majority of whom were assumed to have psoriasis. The list included all persons who had contacted the Foundation requesting information about psoriasis. There was coding for active and inactive membership, active membership being defined as any person who had donated to the Foundation. No attempt was made to collect a random sample.

Because it was assumed that inactive members would be less likely to participate in a personal interview, only active members were drawn as part of the interview sample. An attempt was made to represent males and females equally in the sample by identifying names on the mailing list as belonging to a male or female. Subjects were selected according to zip code areas for the Portland and Eugene metropolitan areas, and Roseburg, in an attempt to represent different social and economic class distinctions. 
Anticipating that some of the sampled members might have moved and some might not have the disease, each interviewer drew, from his assigned zip code area, forty names with the expectation of completing twenty interviews. This also allowed for possible refusals. In addition, the staff of the Foundation recommended members whom they felt would be good people to interview, and gave several interviewers the names of new members who were not on the mailing list.

Known limitations of the method of sampling were:

(1) members were not all psoriatics, and (2) due to the cost of mailing list printouts, and limited budget of the Foundation, the mailing list was not as up-to-date as it might have been.

Procedure for Data Collection

An introductory letter was sent out by the Foundation to those members selected for personal interviews. The letter explained that a survey was being conducted through their office regarding psoriasis, and that the member would be contacted by a person working with the Foundation. A copy of this letter is presented in the Appendix.

Data collection occurred during the months of July and August. Interviewers attempted to notify respondents first by phone, and if this was unsuccessful, went directly to their homes. A note was left requesting that the respondent notify the interviewer to make contact. If this proved unsuccessful, one other attempt was made by the interviewer 
to make contact. If no contact was made, a replacement was used.

For those respondents who agreed to be interviewed, the schedule items were read and the subject's responses were recorded by the interviewers on the interview schedule. The length of the interviews ranged from about forty-five to ninety minutes, depending on the verbal responsiveness of the subject.

Each interviewer was responsible for reviewing his own completed schedules, and recording his progress.

\section{Data Analysis}

Both closed and open-ended questions were to be coded. Open-ended responses were to be categorized for analysis by a process of discussion and joint agreement as to the categories and classifications of responses.

The students were interested in testing for significant differences and relationships within and between the five sections of the instrument.

The statistic to have been employed to determine whether significant differences existed between the variables was to have been the chi square.

The statistic that was to have been employed to determine whether significant relationships existed was the correlation coefficient phi. 
THE CRITIQUE

In this section, the procedures involved with critically evaluating the original study are considered.

In order to critique the original study it was necessary to: (1) review the literature regarding survey research methods and exploratory studies, (2) develop a format (instrument) to systematize the critique, (3) review project records and notes, (4) conduct regular meetings of the students to discuss and share perceptions of the original study, and (5) reach a consensus on each item of the critique to increase reliability of the critique.

\section{Format (Instrument)}

Format of the critique was developed by the students after reviewing formats for assessing research as presented by Kerlinger (1964), Fischer (1975), and Babbie (1973). Since the original study was survey research, included are those items that are essential for good survey research. The following topical outline guided the critique.

I. Research Group

A. Composition and Orientation

B. Problems

II. Problem Formulation
A. Purpose of the Study
B. Auspices 
C. Orientation of Researchers and Use of the Literature

D. Research Questions

E. Hypotheses and Variables

III. Research Design and Data Collection
A. Design
B. Survey Population
C. Sampling Methods
D. Interview Schedule
E. Reliability and Validity of Criterion Mea- sures
F. Pre-test
G. Data Collection

IV. Data Analysis
A. Pre-coding
B. Statistics

Review of the Literature

The review of the literature will not be presented separately, but will be presented as part of the critique.

\section{Review of Project Records} and Notes

No central record for the original project was kept. Each student researcher kept her own personal notebook, where she maintained an ongoing record of the project. These were reviewed at group meetings. 
CHAPTER III

THE CRITIQUE

In this chapter we will evaluate specific features of the study.

\section{THE RESEARCH GROUP}

\section{A. Composition and Orientation}

The original group was composed of three social work students, an instructor from the School of Social Work, and a research assistant. The faculty member was the students' practicum advisor, as well as the primary investigator for the project. The research assistant was hired for the purpose of assisting in data gathering and analysis.

The National Psoriasis Foundation was represented by the director, a staff member, and the advisory board. One member of the board met with the team once during the planning stages.

The research assistant was primarily concerned with demographic information and the issue of the day care center, and minimally interested in the sociological and psychological aspects of the disease which were the focus of the students. The primary investigator attempted to mediate the interests of all concerned so that the project would 
fill the needs of its participants, and satisfy the Foundation's requirements for a data base for future funding requests.

Before the collection of data began, two more members were added to the research team. A medical student was brought in by a member of the advisory board to assist in the interviewing. Douglas County Health Department sent their interviewer, who had been hired for the summer to complete their part of the project. This interviewer met with the team once. Neither of these persons was given the time to become adequately oriented to the study.

B. Problems in Carrying Out the Study

With the sudden resignation in May of the primary investigator from the faculty of the School of Social Work and the project, the students were without faculty supervision and support. The research assistant was appointed to the position of primary investigator.

By midsummer, there was open conflict between the staff of the Foundation and the new primary investigator. Poor communication and disagreement over procedures between these two factions intensified.

In late August, the advisory board of the Foundation terminated the employment of the primary investigator, and the project was tabled. One of the most prominently stated reasons was the poor response on the mail questionnaire, 
which had been sent out third-class mail, and without an explanatory cover letter.

In retrospect, it seems clear that there was an inadequate working agreement between the sponscring agency and the research team in regard to definition of roles, responsibilities, and mutual expectations. Such an agreement possibly existed informally between the original primary investigator and the Foundation, since he himself was a board member. In his absence, however, it was not clear to the team. Students would be well advised to see that projects undertaken for outside agencies should include a written agreement of what is expected of them, and what they can expect of the agency.

Within the research team itself, problems arose in regard to decision making, dealing with conflict, and failure of individuals to carry out their responsibilities. There were no procedural guidelines established for dealing with these situations. We would recommend that research teams establish such guidelines in advance. We would also recommend that the strengths and weaknesses of team members be evaluated, and assignments made according to what each is best equipped to contribute. This was not done in this study. 


\section{PROBLEM FORMULATION}

\section{A. Purpose}

The authors believe the purpose of this study was clear, that the National Psoriasis Foundation desired to know what the needs of its members were, and whether or not a day care center would be utilized.

\section{B. Auspices}

As stated above, the sponsoring organization in this study was clear, and the location of the study stated. C. Orientation of Researchers
and Use of the Literature

The students had limited knowledge about psoriasis when the project started. In order to formulate assumptions and research questions, a thorough search of the literature was made, films describing the disease were viewed, and staff members of the Foundation interviewed. The result of this was an assumption on the part of the students that individuals suffering from psoriasis were negatively affected because of it in some areas of their lives. This was an appropriate method of problem investigation and formulation.

\section{Research Questions}

The research questions regarding the effect of psoriasis in the areas of personal, family, social, community, and economic were appropriately linked to the assumptions drawn from the literature. However, the number of questions 
involved were excessive for the scope of this study. As Fischer (1975) states:

The statement of the research problem--the question(s) to be investigated--and its relation to other research should be clearly formulated. This formulation actually guides the conducting of the study for it is from the research question that the major concepts, hypotheses to be investigated and the selection of an appropriate design proceeds.

Research questions need to be realistically adjusted according to time and funding available, as well as the availability of personnel who will be involved.

E. Hypotheses and Variables

The researchers did not formalize any hypotheses. It was planned that the study itself would result in the formulation of hypotheses for future study. Fischer (1975) states that in the exploratory study:

Generally, hypotheses are not well conceptualized (since they are being sought for), and the research method is flexible, although there may be some fairly systematic procedures for data collection.

Attempts were made to operationally define the dependent variables (the six life areas). The independent variable (suffering from psoriasis) was not defined in a manner which would allow for significant conclusions, in that the severity of the disease was not measured, only its presence. The lack of stated hypotheses, and inadequate operational definition of the independent variable made further formulation of hypotheses from the data unsound. Fischer (1975) states that: 
Both (independent and dependent) variables should be identified conceptually (say, in "theory") and operationally, i.e., the actual means or methods by which the independent variable with affect the dependent variable.

We also note there was no control for confounding variables.

\section{RESEARCH DESIGN AND DATA COLLECTION}

A. Design

The authors believe the exploratory survey design was appropriate for this study due to the lack of research in this area. As Fellin (1969) states:

Exploratory studies are empirical research investigations which have as their purpose the formulation of a problem or a set of questions, developing hypotheses, or increasing an investigator's familiarity with a phenomenon or a setting, to lay the basis for more precise future analysis.

\section{B. Survey Population}

The Foundation's mailing list was used as the survey population. This list was somewhat dated, and did not distinguish between those who actually had psoriasis, and those who did not. More reliable results could have been obtained by choosing another population, such as those persons who had sought medical help for psoriasis at certain designated clinics during a certain time period, for example. Another option would have been to do preliminary survey work with the Foundation's list in preparation for its use. 
C. Sampling Methods

The sample was drawn from the mailing list of the Foundation in a stratified manner by zip code. No attempt was made to draw a random sample. Additional factors known to bias the sample were: (1) staff members recommended members on the mailing list they thought would be responsive subjects; (2) there was coding for active and inactive membership, and active members were overrepresented in the sample because of the assumption that they would be more interested in the project; (3) an attempt was made to balance male and female representation; and (4) persons with telephones were chosen over those who had none.

Failure to draw a random sample made it impossible to determine the true frequency distribution or obtain meaningful findings. Had the study been completed, it would not have been known how much of the statistical result was due to a sampling bias. In addition, by equalizing the sample of male and female subjects, the relative distribution in the population was lost. Babbie (1973) notes that:

A sample will be representative of the population from which it is selected, if all members of the population have an equal chance of being selected in the sample.

\section{Interview Schedule}

The choice of the personal interview for data collection is viewed positively by the authors. As Kerlinger (1964) puts it, "The personal interview far overshadows the 
others (methods) as perhaps the most powerful, and useful tool of social scientific survey research."

The interview schedule used in this study, however, did not properly address the previously formulated research questions. The authors observe that, for example, none of the schedule questions directly addressed the effect of psoriasis on family life, which was one of our original research questions.

Kerlinger (1964) and Babbie (1973) would both support the order of the questions, which was to begin with neutral demographic items. Both authors note that beginning with neutral data helps the interviewer to establish rapport with the respondent, making it easier to move into more sensitive material.

The schedule contained both subjective and objective material, and closed and open-ended questions. We believe the schedule would have yielded more valuable information had more of the questions been put in open-ended form as originally conceived. Kerlinger (1964) states that:

Open-ended questions are flexible: they have possibilities of depth; they enable the interviewer to clear up misunderstanding (by probing); they enable the interviewer to ascertain a respondent's lack of knowledge, to detect ambiguity, to encourage cooperation and achieve rapport, and to make better estimates of respondent's true intentions, beliefs, and attitudes. They also have another advantage: the responses to open ended questions can suggest possibilities of relations and hypotheses. 
E. Reliability and Validity

of Criterion Measures

A significant deficiency in the schedule was the lack of instructional and introductory material in written form for both interviewer and respondent. Babbie (1973) states that ideally an interviewer should be able to conduct an entire interview without ad-libbing a single word. He adds that all transitional statements throughout the questionnaire should be included so that the verbatim script sounds natural and conversational. Even probe questions, he adds, should be limited to specific written probes. The omission of these items on the schedule led to individualized instructions and explanations by each interviewer, seriously affecting the reliability of the completed questionnaires.

Many of the questions did not address the issues of reliability and validity during their formulation. Kerlinger (1964) specifies numerous criteria for question writing. Some of these, and examples of each from the schedule, are given below.

"Is the question clear and unambiguous?" Question 11 asks, "How severe would you describe your psoriasis?" The respondent does not know if he is being asked about the present state of the disease, or what it is like when it is at its worst.

"Is the question a leading question?" Question 27: "Have you ever sought counseling because of stress due to your psoriasis?" We can see in retrospect that we 
were attributing stress to the respondent, who might or might not perceive himself as experiencing it. Also, leading questions suggest answers, and as such threaten validity.

"Does the question demand knowledge and information that the respondent does not have?" Question 40 asks, "What services would you like to see provided by a Psoriasis Day Treatment Center?" Most respondents were not familiar with what such a center was until they were informed by the introduction to question 37 . They cannot be expected to have formulated we11-thought-out answers to this question in a few minutes.

"Does the question demand delicate or personal material that the respondent may resist?" Question 25 inquires, "Has your psoriasis interfered with your sexual relationships?" It is difficult to justify this question in a broad preliminary study of this type. Several of the interviewers excluded this question in dealing with elderly and some single persons, considering it inappropriate.

Other problems noted in the questions were: (1) the use of "yes/no" or "ever" responses followed by the openended feature, when a scale would have been more valuable (question 24); (2) failure to measure the degree of severity of the psoriasis as related to the effect on the respondent (question 22); (3) asking two questions within one 
question (question 31); and (4) starting questions with a biased statement. Number 30 , for example, states that many people find treatment for psoriasis expensive. The respondent is then asked if he finds his treatments are expensive. In addition to the bias, there is no measure for what expensive means, so that it could be measured objectively in some sense.

In reviewing our experience in being a part of the construction of this schedule, the authors must agree with Kerlinger (1964):

Interviewing itself is an art, but the planning and writing of an interview schedule is even more of an art. It is unusual for a novice to produce a good schedule, at least without considerable prior study and practice. There are several reasons for this, the main one being the multiple meaning and ambiguity of words, the lack of sharp and constant focus on the problems and hypotheses being studied, a lack of appreciation of the schedule as a psychometric instrument, and a lack of necessary background and experience.

F. Pre-test

A pre-test was carried out for the purpose of eliminating clumsy wording in questions. Only minor modifications were made in several questions as a result of the pretest.

G. Data Collection

Data collection commenced with the sending out of an introductory letter to those persons who were to be 
interviewed. This is viewed by the authors as an appropriate procedure.

Data collection took place during the months of July and August. According to Farber and Nall's study of fiftysix hundred persons suffering from psoriasis, approximately three-fourths were either better, or in a state of remission in hot weather (1974). It might be speculated that the concern of many respondents at this time of year might be minimal concerning their disease.

Interviewer training was minimal, and along with the absence of written instructions on the schedule, led to inconsistency of approach to the respondents, as noted earlier. The interviewer from Roseburg was not brought in for any training at all, although this had been planned. This led to apparent confusion on her part as to what her role was, and it was later learned that she had mailed out part of her questionnaires instead of carrying them out as personal interviews. Babbie (1973) tells us that:

Interviewer training should be done in a group... The interviewer training session should begin with a description of what the study is all about... Morale and motivation are usually low when interviewers do not know what is going on.

There was no supervision to see if the interviews had been carried out, or if they had been carried out appropriately. Babbie (1973) tells us that all or a portion of the interviews should be verified by a supervisor. There was no method of systematically recording data, with each 
interviewer being responsible for his own, and using his own system. This is seen as poor procedure.

\section{DATA ANALYSIS}

\section{A. Pre-coding}

According to Babbie (1973), the questionnaire should be pre-coded to facilitate data processing. This was not done.

\section{B. Statistics}

While chi square and phi might have been appropriate for the nominal data, much information would have been lost by not using measures appropriate to the interval data elicited. Also, there are many statistical measures for nominal, ordinal, and binomial data which yield more refined results.

\section{SUMMARY}

In our critique we have addressed what we considered to be the major problems that developed in carrying out the original study. Although we have attempted to be as thorough as possible, the authors expect that the reader might identify additional problems which have not been addressed. 
CHAPTER IV

\section{SURMARY AND CONCLUSIONS}

The first section of this chapter is a summary of our principal findings. The second section contains some implications of the study.

\section{SUMMARY OF FINDINGS}

An inadequate contract existed between the participants in the research project and the sponsoring organization, resulting in confusion as to roles, responsibilities, and 1 ines of authority. Students should seek a written agreement which defines these areas when taking part in a research project for an agency, or other organization outside the school.

There was a lack of organization in the research team itself so that procedures were unclear as to how to deal with conflict, or members who were not fulfilling individual responsibilities. Such procedures should be clearly defined in the early stage of a project.

There was no attempt to take into account the strengths or weaknesses of individual team members in assigning tasks. This did not utilize the full potential of the team. 
The research questions were appropriately linked to the literature, but too broad in scope to be adequately covered by this study. Research questions should be realistically adjusted to the time, funding, and personnel available for a particular study.

Dependent and independent variables were not properly defined, nor hypotheses stated. Improper problem formulation led to faulty procedures throughout the rest of the study.

The exploratory survey design was an appropriate choice for the study.

The actual universe of the population used in the study was unclear. Therefore, it was not possible to draw an appropriate sample.

The sample was not drawn randomly, limiting the significance of the findings for the population.

The interview schedule was an appropriate choice for the study, but was lacking in instructional material for the interviewer and respondent, limiting its reliability.

Many of the questions did not address the issues of reliability and validity in their formulation.

Interviewer training was not uniform for all team members, and was inadequate.

There was a lack of efficiency in keeping track of the progress of the study, and the activities of individual team members. 
Proposed data analysis was not adequate for the type of information elicited.

\section{IMPLICATIONS OF THE STUDY}

Implications for the Education

of Social Work Students

Students are often not prepared to do a master's level research paper when they begin the practicum or thesis, and must do much learning within the process. It might be in the interest of better education to emphasize the teaching of research methodology at the undergraduate level.

Another concern is the extent of responsibility of the administration of the school when students take part in projects for outside agencies or organizations, such as this study. It is felt by the authors that there should be more control by the school over the quality of such projects, and that the responsibility of the administration, the students, the advisor, and outside directors should be clearly spelled out.

\section{Implications for the Field} of Social Work

If the profession is to have reliable information, proper methodology in research must be attended to, since this is the basis for judging the validity of studies. Administrators must be able to count on the results of studies in using them for planning and funding purposes. In addition, large amounts of money can be wasted on meaningless 
research if the methodology is inadequate. A demand by those sponsoring research that it meet the requirements of good research will further the efforts of social work as a field.

Implications for Further Research on Psoriasis

In doing this study, we conclude that there is a need for further social work research on the effect of psoriasis on individuals. This research should include the attitudes of the general public toward this disease, and the reasons behind these attitudes. There should also be investigation as to whether or not factors associated with other dermatological diseases might apply here, also.

We are not sure how many persons do not come in for treatment because of stigma, or hopelessness about improvement in the condition. Only with understanding backed by reliable research can social workers bring about change.

Conclusion

While perhaps few studies may present as many difficulties as this one, much grief can be avoided by adequate knowledge and application of research design and methodology. 


\section{REFERENCES CITED}


Babbie, Earl R. Survey Research. Belmont, Calif.: Wadsworth, 1973 .

Baughman, R., and Sobel, R. "Psychological Factors Relating to Psoriasis." In Process of the International Symposium on Psoriasis, pP. 61-67. Edited by E. Farber and A. Cox. Stanford, Calif.: Stanford University Press, 1971 .

Braun-Falco, 0.; Bur, G; and Farber, E. M. "Psoriasis: eine Fragebogenstudie 536 Patienen." Much, Med. Wshr. 114 (1972) : 1-15.

Cole, William. "Psoriasis." Family Health, July 1974, pp. 24-52.

Coles, R. B., and Ryan, T. J. "The Psoriasis Sufferer in the Community." British Journal of Dermatology 93 (1975): 111 .

Farber, E. M., and Bright, R. D. "Psoriasis." Archives of Dermatology 100 (1969):674-76.

Farber, Eugene M., and Na11, M. Levie. "The Natural History of Psoriasis in 5,600 Patients." Dermatologica 148. (1974):1-18.

Farber, Eugene M., and Carlsen, Ray A. "Psoriasis in Childhood." California Medicine 105 (1966):415-19.

Fellin, Phillip; Tripodi, Toni; and Meyer, Henry J., eds. Exemplars of Social Research. Itasca, I11.: F. E. Peacock Publishers, Inc., 1969.

Fischer, Joel. Analyzing Research: A Guide for Social Workers. Honolulu: University of Hawaii, 1975.

Goldsmith, Lowell A.; Fisher, Michael; and Wacks, Jerry. "Psychological Characteristics of Psoriatics." Archives of Dermatology 100 (1969):674-76.

Graham, David T. "The Relation of Psoriasis to Attitude and to Vascular Reactions of the Human Skin." Journal of Investigative Dermatology 22 (1954):379-88. 
Jobling, R. G. "Psoriasis--A Preliminary Questionnaire Study of Sufferers' Subjective Experience." Clinical and Experimental Dermatology 1 (1976): 233 .

Kerlinger, Fred. Foundations of Behavioral Research. New York: Holt, Rinehart, and Winston, 1964.

Mackenna, R. M. B. "Psychosomatic Factors in Cutaneous Disease." Lancet 2 (1944):679.

Moos, Rudolf $\mathrm{H}$., ed. Coping with Physical I1lness. New York: Plenum Medical Books, 1977.

National Psoriasis Foundation. Background Information: Psoriasis. Portland, Ore.: National Psoriasis Foundation, 1976. (Mimeographed.)

Nyfors, Allan, and Lemholt, Klans. "Psoriasis in Children." British Journal of Dermatology 92 (1975): 437 .

Obermeyer, M. E. Psychocutaneous Medicine. Springfield, I11.: Charles C. Thomas, Publisher, 1958.

Thompkins, Robert. "Psoriasis, A Status Report." Pennsylvania Medicine 76 (October 1973): 56 .

Savin, J. A. "Patients' Beliefs about Psoriasis." Transactions of the St. John's Hospital Dermatological Society $56(1970): 139-42$.

Susskind, W., and McGuire, R. J. "The Emotional Factors in Psoriasis." Scottish Medical Journal 4 (October 1959) : 503-7.

Wittkower, E. "Psychological Aspects of Psoriasis." Lancet 1 (1946) : 566-69. 
APPENDIX 


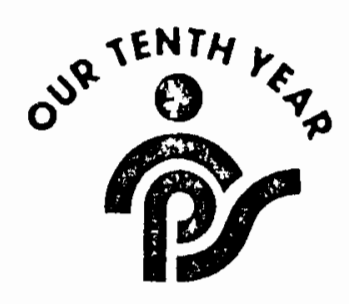

July 10,1978

Dear Friend,

The National Psoriasis Foundation and The School of Social work at Portland State University, are doing a survey of people's reactions to psoriasis.

We will be contacting you to arrange an interview at your convenience. We feel that the results of this survey will be inportant in furthering the treatment of psoriasis and helping psoriatic sufferers to live an easier and better life.

Thank you for your cooperation in advance.

Sincerely,

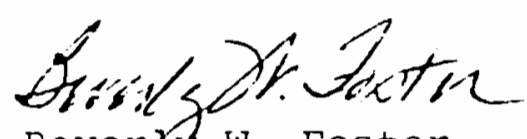

Bever2 W. Foster

Founder/Executive Director

$B W F: k f$ 


\section{National Psoriasis Foundation}

N. W. PSORIASIS SURVEY

1. Age: Please Check One

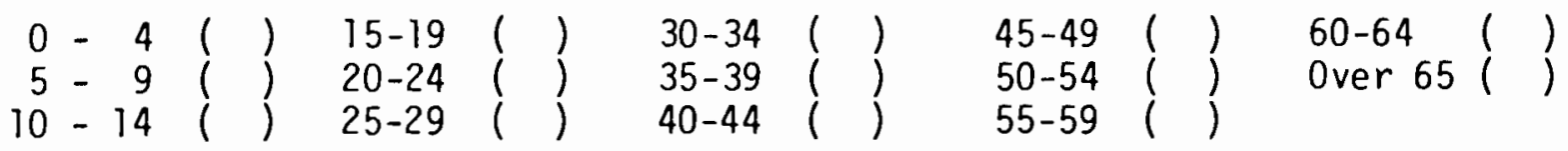

2. Sex:

Male
Female ()

3. Marital Status: Please Check One

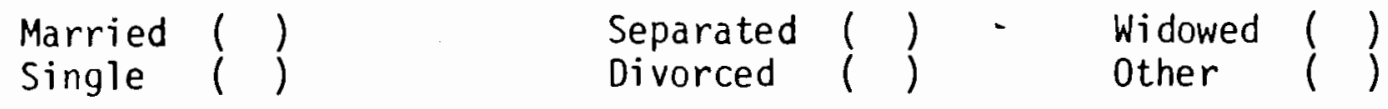

4. Occupation: (Specific Industry)

5. Level of Income:

$\begin{aligned} & \text { Under } \$ 5,000 \\ & \$ 5,000-\$ 9,999() \\ & 10,000-14,999() \\ & \$ 15,000-\$ 19,999(), 000-\$ 24,999 \\ & \$ 20, \\ & \$ 25,000-\$ 29,999()\end{aligned} \quad \$ 30,000$ \& Over ( )

6. Education: Please Check One

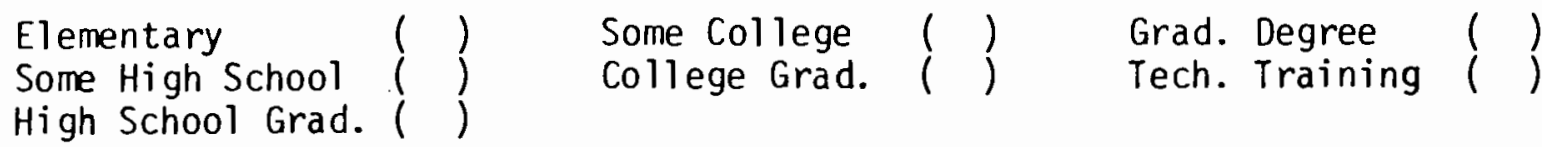

7. Race: Please Check One
Black ()
White
Amer. Indian ()
Hispanic
$\left.\begin{array}{l}\text { Oriental } \\ \text { Other }\end{array}\right)$

8. Age at which psorias is began:
$0-4$
$5-9$
$10-14$
$15-19$
$20-24$
$25-29$()
$\begin{array}{ll}30-34 & (\quad) \\ 35-39 & (\quad) \\ 40-44 & ()\end{array}$
$45-49$
$50-54$
$55-59$
$60-64$
Over 65()

9. Did anything happen to bring on your psoriasis?
$\left.\begin{array}{l}\text { Fever } \\ \text { Il lness }\end{array}\right)$
Sunburn
Emotional Stress ()
$\begin{array}{ll}\text { Injury } & (\quad) \\ \text { Other }\end{array}$

10. Do any other family members have psoriasis? Yes ( ) No ( ) If yes, which members? 
11. How severe would you describe your psoriasis?

Very Mild ( ) Mild ( ) Moderate ( ) Severe ( ) Very Severe ( )

12. Is your psoriasis active at the present time?

Yes () No $($ )

13. Has your psoriasis increased in severity since initial onset?

Yes $(1) \quad$ No $(1)$

14. Is your psoriasis limited to specific areas of your body? Describe

15. Does your psorias is affect certain parts of your body that are more troublesome to you than other areas? (Probe)

16. What areas of your life have been most affected by psoriasis?

17. Has your psoriasis affected your ability to obtain work?

Yes ( ) No ( )

If so, how?

18. If you work, would you have selected another occupation if you had not had psoriasis?

Yes ( ) No ( ) Had not thought about it ( )

What other occupation would you have selected? 
19. Has your psoriasis kept you from participating in such community 47 activities as swimming in public pools, going to a beauty or barber shop, trying on clothes in stores, etc.?

20. Do you feel that other people think psoriasis is contagious?

Yes () No () Don't know ()

21. Do you feel other people treat you differently because of your psoriasis?

Yes () No ()

If yes, explain how.

22. Some people feel embarrassed by their psoriasis, while others do not. Do you ever exclude yourself from social activities because of your psoriasis?

Yes ( ) No ( ) PROBE --what activities? If so, do you do this only when your psoriasis is in an active state?

23. Does psoriasis affect how you feel about yourself? Probe--How? Under what circumstances.

24. Has your psoriasis ever affected your social relationships, and how?

25. Has your psoriasis interfered with your sexual relationships?

Yes () No () In what way? 
26. IF MARRIED: Has your psoriasis caused any particular problems between you and your spouse? If so, what kinds of problems?

IF UNMARRIED: Do you think psoriasis has interfered with the possibility of your becoming married?

27. Have you ever sought counseling because of stress due to your psoriasis? Yes ( ) No ( ) Was it helpful? If not, why not?

28. Have you ever been treated for psoriasis? Yes ( ) No ( ) If yes, by whom?

Druggist ()
Osteopath
Chiropractor () $\quad \begin{aligned} & \text { Family Physician } \\ & \text { Dermatologist } \\ & \text { Dietitian }\end{aligned}() \quad \begin{aligned} & \text { Naturopath } \\ & \text { Other } \\ & \text { Specify }\end{aligned}()$

29. Have you ever been told psoriasis is untreatable? Yes ( ) No ( ) If so, by whom?

30. Many people find that treatment for psoriasis is expensive. Do you find that your treatments are expensive? Yes ( ) No ( ) Has the expense kepy you from treating your psoriasis? Yes ( ) No ( )

31. What type of treatments do you use? Do you feel that these treatments are the best available? (PROBE)

32. Do you carry any kind of health insurance? What kind?

33. Does your health insurance cover any of the treatments you use for psoriasis? Yes () No $(1)$ Which ones? 
34. Have you ever been hospitalized for psoriasis? Yes ( ) No ( )

35. Are treatment facilities available for you in your immediate area?

Yes () No $(1)$

36. Have you ever heard of Psoriasis Day Treatment Centers? Yes ( ) No ( ) If yes, what is your opinion of them?

37. Such Centers may provide a wide range of medical, social, and psychological services during the day, allowing patients to return to their families and regular activities in the evening.

If such a Center were available to you, would you use it?

Yes ( ) No ( ) If not, why not?

38. How far would you be willing to travel for treatment?

39. If such a Center were available in the Northwest, in which city and state would you like it to be located?

First Choice

Second Choice

40. What services would you like to see provided by a Psoriasis Day Treatment Center? 
41. In addition to treatment services, what other services would the Center need to provide to make it possible for you to attend the Center?

Interviewer Comments: 